\title{
Development of a kriging assessment framework and impact pathway for researching contamination with potentially toxic elements in urban landfill soil
}

Azizi Abu Bakar ( $\square$ azizi.bkr@um.edu.my )

Universiti Malaya https://orcid.org/0000-0003-4794-7907

Minoru Yoneda

Kyoto University: Kyoto Daigaku

Noor Zalina Mahmood

Universiti Malaya

\section{Short Report}

Keywords: environmental risk assessment, guess-field kriging, heavy metal, impact pathway, landfill aftercare

Posted Date: February 10th, 2022

DOI: https://doi.org/10.21203/rs.3.rs-1053828/v2

License: (9) This work is licensed under a Creative Commons Attribution 4.0 International License. Read Full License 


\title{
Development of a kriging assessment framework and impact pathway for researching contamination with potentially toxic elements in urban landfill soil
}

Azizi Abu Bakar'* , Minoru Yoneda² and Noor Zalina Mahmood ${ }^{3}$

${ }^{1}$ UM Community Engagement Centre - UMCares, Universiti Malaya, 50603 Kuala Lumpur, Malaysia

${ }^{2}$ Laboratory of Environmental Risk Analysis, Department of Environmental Engineering,

Graduate School of Engineering, Kyoto University at Katsura, Nishikyo-ku, Kyoto 615-8540, Japan

${ }^{3}$ Institute of Biological Sciences, Faculty of Science, Universiti Malaya, 50603 Kuala Lumpur, Malaysia

*Corresponding author:
Email address: azizi.bkr@um.edu.my / azieaxis@gmail.com (A.B. Azizi)

\begin{abstract}
Landfill post-closure with contaminant concentration in soil below permissible limit assessed at limited spot does not represent the contamination issue. Assessment limit to professionals also does not gives a potential of change to practice constant assessment to a wider context of assessor - citizen living nearby - as a collaborative effort to sustain a safe environment. Therefore sizeable, qualitative, and cost-effective analysis of the concentrations of contaminants is needed and this work recommends kriging assessment and the logical impact pathway framework as factors of change in landfill aftercare management. The kriging framework is developed utilising lead $(\mathrm{Pb})$ and chromium (Cr) data from inductively coupled plasma mass spectrometry (ICP-MS) analysis. The development of the kriging framework is conducted based on the observation of censored data from ICP-MS analysis. The estimation analysis involves the analysis of ordinary kriging with regression analysis, showing the interpolation of spatial correlation and regression error. Hence, ordinary kriging with regression of the variable of interest, i.e., $\mathrm{Pb}$, using the data of the explanatory variable, i.e., $\mathrm{Cr}$, is inappropriate. Further investigation with the utilisation of guess-field kriging analysis hypothetically exposed a potential contaminated area using an existing but limited number of explanatory variables; although, guess-field kriging may possibly result immense uncertainty at the area where the explanatory variable does not exist. Besides, this work anticipated outcomes in societal impact and sustainability practices from the proposed kriging framework by recommending a logical impact pathway. The development of the kriging framework and impact pathway reassure the necessary actions to be executed by
\end{abstract}


responsible parties and act as the stimulus of a wider spectrum of improvement initiatives to oversee real issues, such as the time of occurrence, and to prevent negative impacts on the environment and humans.

Keywords: environmental risk assessment; guess-field kriging; heavy metal; impact pathway; landfill aftercare 


\section{Development of a kriging assessment framework and impact pathway for researching contamination with potentially toxic elements in urban landfill soil}

\section{Introduction}

A closed landfill is known for its potential risks to ecosystems, and other than its detrimental impact on the environment, particularly at the adjacent polluted area (Vaccari et al. 2018), the contaminants present in the landfill has the potential to affect human health (Hussein et al. 2021). It has been reported that the waste materials buried in landfills may potentially be the cause of birth abnormalities and genetic problems and could increase the risk of cancerous diseases other than that, results in high mortality risk particularly for people residing at close proximity or near landfill areas (Chervona 2012; Rushton 2003). Exposure to potentially toxic elements poisons the human body via different pathways, resulting in no known benefits and the deterioration of individual health (Li et al. 2014; Mombo et al. 2015; Zhang et al. 2012). Moreover, the risk of potentially toxic element contamination can potentially be more severe as a result of heterogeneous waste dumped in a non-sanitary landfill. There have been various studies in Malaysia that have discovered the effects of potentially toxic elements in the soil of an operating landfill, but few works have reported this information for closed landfill sites (Agamuthu and Fauziah 2010; Hussein et al. 2021; Mohd Adnan et al. 2013; Sakawi et al. 2013; Syahirah et al. 2013; Taha et al. 2011; Yusoff et al. 2013).

The analysis of a potential contamination area in a closed landfill is necessary to prevent contamination and pollution. Geostatistics analysis by applying kriging is helpful in identifying the possible contamination area by estimation and a decision-making process. The geostatistics methodology can be applied to allow us to ascertain the dependent variable set at any location in an area and the uncertainty of the statistical interpolation as an instrument to judge the most appropriate and possible interpolation (Gamez et al. 2019). Kriging interpolation, as part of geostatistics, known as a best linear unbiased interpolator technique for examined data for unvisited area, and it performs variogram or spatial modelling by utilising original values on structural characteristics and partition variables (Zhao et al. 2021). Author keywords analysis of co-occurrence using VOSviewer (version 1.6.16) network visualisation for the Web of Science (WoS) core collection by Thompson Reuters Corporation (USA), on April 5, 2021 showed that keyword of "kriging" is closely related to keyword of "soil" in database of publication collection year within the time frame of 1970-2020. The result from the analysis shows a representation of the keywords with large bubble, label and interconnected with links on selected keywords, i.e., "area", "spatial-distribution", "contamination", "pollution" and "risk assessment" (Fig. 1a). In addition, from the 
overlay visualisation (Fig. 1b) shown that there is connection for keywords of "urban soils", "agricultural soils", "spatial distribution", and "risk assessment" from the year of 2016 and beyond (indicated by yellow bubbles). This analysis is crucial to understanding the development of research related to the keywords and to identifying core areas or acknowledged hotspots in the kriging research setting by presenting a fundamental connection among keywords in related research papers (An and $\mathrm{Wu} 2011$ ).

Other than the research development and hotspots of the utilisation of the kriging analysis, this work aimed to initiate better management initiatives of landfill aftercare by developing a framework for assessing contamination of potentially toxic element in landfill topsoil and recommend it to be outfitted as a decisionmaking procedure. As a consequence of the development of the framework, drawing a logical scheme of planning, i.e., pathway to impact from the kriging analysis is developed in order to plan for desirable impact.

\section{Materials and methods}

\subsection{Description of the closed landfill}

The largest population state in Malaysia, Selangor, with area of $7,951 \mathrm{~km}^{2}$ and 6.53 millions of population (Department of Statistics Malaysia, 2022). Selangor state is the main municipal solid waste producer for the nation's total waste with $33.3 \%$ (Sharifah-Norkhadijah et al. 2009). Furthermore, the state is presently encountering a critical crisis of waste disposal as the state is the receiver of waste from Kuala Lumpur city, due to the city has scarcity of location for landfilling (Sharifah-Norkhadijah et al. 2013). To date, there are twentytwo landfills reported to be present in the Selangor state with eight landfills operating and fourteen are ceased for operation (National Solid Waste Management Department 2022). A closed urban non-sanitary landfill located in Sepang, Selangor, i.e., Ampar Tenang landfill, was selected for this study. The landfill was served non-segregated refuse from the Federal Territory of Kuala Lumpur, and other cities in Selangor state together with mixed municipal waste from Federal Territory of Putrajaya, the federal Malaysian administrative centre.

The closed urban landfill of Ampar Tenang situated in the suburban district of Sepang, south of the principal cities of Klang Valley or Greater Kuala Lumpur region, i.e., Kuala Lumpur city centre and Putrajaya (Fig. 2). The landfill geographical zone is skirt around with a palm oil plantation, and at eastern bank of Labu River (a tributary of Langat River) with latitude $2^{\circ} 49^{\prime} 06.9^{\prime \prime} \mathrm{N}$ and longitude $101^{\circ} 40^{\prime} 47.8^{\prime \prime} \mathrm{E}$. Active real estate development is being constructed and existing residential zone surrounding adjacent areas of the plantation. The landfill initially an open dump area or closed open-tipping site categorised as Level 0 (L0) and then upgraded to a controlled waste disposal site with Level 1 (L1) status (Ministry of Housing and Local Government 2004; Mohd Adnan et al. 2013). 
The landfill started operation in the year 2000 and it is reported to schedule closing in 2006, however it was operating till it was obstructed and authoritatively ended operation in 2010 (Krishnan 2008; Mohd Adnan et al., 2013). During the ten years of operation period, the site accumulated approximately 100 tonnes of municipal solid waste per day (waste thickness range: 4.5 - 9.0 m) uncovered with no engineered linear material system (Elwali et al. 2010; Taha et al. 2011). The landfill was initially managed by Sepang local authority and was then assigned to a private limited company for cessation of operation and maintenance.

\subsection{Soil sampling}

Sampling of the closed landfill surface soil (mixture of topsoil and subsoil at depth $30 \mathrm{~cm}$ from surface of the closed landfill) utilising stainless-steel shovel were conducted in November 2016 to March 2017 (during northeast monsoon in a tropical climate). Square grid $(5 \mathrm{~m} \times 5 \mathrm{~m})$ (insert in Fig. 2) was used as sampling design. One sample at approximately the centre of the grid for each grid was taken for analysis.

\subsection{Laboratory analysis}

Collected soil samples were prepared by fifteen minutes of sterilisation in autoclave at $121^{\circ} \mathrm{C}$ prior air drying under room temperature. Samples were then powdered in an agate mortar and sieved after constant weight of airdried soil samples were achieved. Approximately $0.5 \mathrm{~g}$ of homogenised soil samples were partially digested for matrix opening with $10 \mathrm{~mL}$ of $\mathrm{HNO}_{3}$ in a microwave digestion system. Dilution with Milli- ${ }^{\circledR}$ water and filtered with cellulose membrane filter of $0.45 \mu \mathrm{m}$ prior to potentially toxic element analysis utilising an inductively coupled plasma mass spectrometry (ICP-MS). Samples were analysed in triplicate and following standard operating procedures to obtain precision in data analysis.

\subsection{Geostatistics}

Procedures to execute geostatistical analysis were conducted as follow (Fig. 3):

\subsubsection{Data exploratory}

In this procedure the potentially toxic element data were analysed using SPSS 24.0 (IBM, Chicago, Illinois, USA) for multivariate and descriptive statistical analyses, i.e., one-sample $t$ test, parametric test, and one-way analysis of variance with significant differences when $P<0.05$. Prior construction of spatial modelling, i.e., variogram, 
data were transformed for convenient of certain types of analyses which if it is back-transform, the data will return to their original state (Yarus and Chambers 2006).

\subsubsection{Spatial modelling}

An exponential model was used in this study for the spatial modelling, as follows:

$\gamma_{2}(h)=c_{0}\left[1-e\left(-\frac{h}{a_{0}}\right)\right]$

here $\mathrm{c}$ denotes sill, $\mathrm{h}$ denotes lag distance and nugget $=0$ were utilised for kriging.

\subsubsection{Kriging}

Kriging is a best linear unbiased interpolator which possess minimal probable estimation variance and the structural information is optimally estimated by using a regionalised sample data. Furthermore, the sample points estimated in kriging have mutual spatial positional relationship (Cui 2016; Zhen et al. 2019). In this work, interpolation in 2D developed from a programming language, i.e., macros utilising Visual Basic for Applications (VBA) in a Microsoft ${ }^{\circledR}$ Office software was conducted for kriging analysis. Types of kriging tested to obtain the best estimate for the potentially toxic element contamination in the topsoil of the closed landfill were ordinary kriging (OK), regression kriging (RK), and guess-filed kriging (GFK).

\section{- Ordinary kriging $(O K)$}

The most unexceptional method used for kriging is ordinary kriging due to its function based on assumption that mean is unknown and interpolate data to primary levels at unsampled locations (Webster and Oliver 2007), the ordinary kriging explains as follows:

Ordinary kriging: $\gamma(h)=\frac{1}{2 N(h)} \sum_{i=1}^{N(h)}\left[Z\left(x_{i}+h\right)-Z\left(x_{i}\right)\right]^{2}$

here $\gamma(\mathrm{h})$ is magnitude of lag distance between location of two samples; $\mathrm{h}$ represents the lag distance which disconnects points that pairing; $\mathrm{N}(\mathrm{h})$ denotes the number of pairs disconnected by the lag distance, $\mathrm{h} ; \mathrm{Z}\left(\mathrm{x}_{\mathrm{i}}\right)$ is a arbitrary variable at location $\mathrm{x}_{\mathrm{i}} ;$ and $\mathrm{Z}(\mathrm{x}+\mathrm{h})$ and $\mathrm{Z}(\mathrm{x})$ represent the existent values at locations 
$\mathrm{x}+\mathrm{h}$ and $\mathrm{x}$, respectively (Bhunia et al. 2018; Lin et al. 2008). The value of $\mathrm{Z}$ at location $\mathrm{X}_{0}$ estimates by ordinary kriging utilising linear combination of $\mathrm{n}$ data, as follows:

$Z_{0}^{\wedge}=\sum_{i=1}^{n} \lambda_{i} Z\left(X_{i}\right)$

- $\quad$ Regression kriging $(R K)$

Regression kriging is commonly employed in regard to its low error of estimation. It also named as simple kriging with changeable local means (Pei et al. 2010). This is effective by improving predictions of regression models with kriging interpolation (Pouladi et al. 2019; Yigini and Panagos 2016). The method is executed by employing regression on supplementary information follow with simple kriging using a known mean to estimate residuals from the regression model (Zhen et al. 2019). Nevertheless, regression kriging has no error of self-correlation but exception to estimation of same variable with a different methodology applied although this case is rare. So, regression is assumed from a response variable and the explanatory variable as in an equation below:

Regression kriging: $Z_{1}(X)=g\left[Z_{2}(X)\right]-\varepsilon(X)$

here $g\left[\mathrm{Z}_{2}(\mathrm{X})\right]$ indicates regression equation and $\varepsilon(\mathrm{X})$ is an error term of an expectation value.

- $\quad$ Guess-field kriging (GFK)

Guess-field kriging is valid to the following regression equation:

Guess-field kriging: $Z_{1}(X)=g\left(Z_{2}(X)\right)+\varepsilon(X)$

here $g\left(\mathrm{Z}_{2}(\mathrm{X})\right)$ indicates regression equation and $\varepsilon(\mathrm{X})$ is an error term of an expectation value. In case of $\mathrm{Z}_{1}(\mathrm{X})$ and $\mathrm{Z}_{2}(\mathrm{X})$ are assessed at similar location, the estimation error $\eta(\mathrm{X})$ can be determined as the following:

$\eta(X)=Z_{1}(X)-g\left(Z_{2}(X)\right)$ 
Assume that $\eta(X)$ and $g\left(Z_{2}(X)\right)$ have by no means of correlation. Kriging estimates $\mathrm{Z}_{0}^{\wedge}$ and kriging variance $\sigma_{k 0^{2}}$ at $\mathrm{X}_{0}$, with the guess-field kriging of the response variable being acquired as the following:

$Z_{0}^{\wedge}=g\left(Z_{0}^{\wedge}\right)_{0}+\eta_{0}^{\wedge} \quad \sigma_{k 0^{2}=} \sigma_{k g 0^{2}+} \sigma_{k \eta 0^{2}}$

where $g\left(\mathrm{Z}_{0}^{\wedge}\right)_{0}$ is the kriging interpolate of $\mathrm{Z}_{1}$ by applying $\mathrm{m}$ transformed data; $g\left(\mathrm{Z}_{2}\left(\mathrm{X}_{\mathrm{i}}\right)\right)(\mathrm{i}=1,2, \ldots)$; $\sigma_{k 0^{2}}$ is the kriging variance; $\eta_{0}^{\wedge}$ is the kriging interpolate of the residual error utilising $\mathrm{n}$ residual error; $\sigma_{k \eta 0^{2}}$ is variance of kriging; and $\mathrm{n}$ is the sampling points number where $\mathrm{Z}_{1}$ and $\mathrm{Z}_{2}$ are both studied.

\subsubsection{Validation}

Estimation from kriging analysis necessitate validation to predict the statistical formation for agreeing the calculation. Validation was directed utilising programming languages in Microsoft ${ }^{\circledR}$ Office, i.e., VBA. Macros utilised for the VBA program presented in Supporting Information.

\subsection{Visual basic for applications (VBA)}

Kriging analysis was assessed in this study by operating the transformed data, prior administered into VBA programs in Microsoft $\mathrm{t}^{\circledR}$ Excel to obtain the concluding estimation. The VBA program principally implement two types of kriging procedures with functional macros in this analysis, i.e., ordinary kriging (OK) and advanced kriging (RK and GFK). Macros utilised for the VBA program presented in Supporting Information.

\subsection{Development of impact pathway}

A logic model of impact pathway is developed as a research tool to facilitate data from kriging assessment to outline categories of payback from research or impact that is beyond academic. The model was adapted from the concept of Payback Framework by Donovan and Hanney (2011), with an adjustment that was appropriate to the kriging assessment circumstances.

\section{Results and discussion}

\subsection{Kriging assessment}

3.1.1. Ordinary kriging $(\mathrm{OK})$ 
Regression combined with kriging analysis were assessed for ICP-MS analysis data of $\mathrm{Cr}$ and $\mathrm{Pb}$ in the topsoil of the studied landfill. This involved interpolating $\mathrm{Pb}$ content by utilising the $\mathrm{Cr}$ analysis result for kriging with regression analysis. In this study, $\mathrm{Pb}$ was the response variable, and $\mathrm{Cr}$ was the explanatory variable. Ordinary kriging framework processed in this work presented in Fig. 4. In this work, analysis is developed to support interpolation of the considered missing of $\mathrm{Pb}$ data as response variable by utilising $\mathrm{Cr}$ data as explanatory variable. The prime reason of using $\mathrm{Pb}$ and $\mathrm{Cr}$ data as response and explanatory variable respectively due to both data had correlation from the same instrument tested i.e., ICP-MS. Ordinary kriging show no clear outline flow of distribution due to the small, estimated correlation (results are not shown).

Semivariogram of explanatory and response variable estimated as follows:

Cr: $\gamma_{\text {Cr }}(\mathrm{h})=0.13 \times\{1-\exp (-\mathrm{h} / 1.5)\}$

$\mathrm{Pb}: \gamma_{\mathrm{Pb}}(\mathrm{h})=0.062 \times\{1-\exp (-\mathrm{h} / 0.8)\}$

Distribution results from ordinary kriging showed large difference due to the assumed missing data is greater than standard deviation. This is reflecting large uncertainty in the distribution of ordinary kriging and the $95^{\text {th }}$ percentile estimate.

\subsubsection{Regression Kriging (RK)}

The analysis flow developed for the regression kriging analysis is shown in Fig. 4. In this study, there was a correlation between $\mathrm{Cr}$ and $\mathrm{Pb}$ with equation:

$\mathrm{Pb}(\mathrm{ICP}-\mathrm{MS})=0.5343 \times \mathrm{Cr}(\mathrm{ICP}-\mathrm{MS})+0.3877$

where $\mathrm{R}^{2}=0.5467$, and the variance of the estimation error is 0.029 . Regression kriging estimates has indicated distribution around the missing data area as compared to ordinary kriging. Nevertheless, no clear outlines in the distribution due to the estimates utilises only semivariogram of $\mathrm{Pb}$ and the regression kriging contains spatial correlation (result not shown). Hence, the distribution from regression kriging estimates is inappropriate to support interpolation of the missing data. 


\subsubsection{Guess-field kriging (GFK)}

The analysis flow developed for the guess-field kriging analysis is shown in Fig. 4. Lead semivariogram for regression estimated as follows:

$$
\begin{aligned}
& \gamma_{\text {reg }}(\mathrm{h})=0.534322 \times \gamma \mathrm{Cr}(\mathrm{h})=0.534322 \times 0.13 \times\{1-\exp (-\mathrm{h} / 1.5)\}= \\
& 0.0371 \times\{1-\exp (-\mathrm{h} / 1.5)\}
\end{aligned}
$$

Regression residual for $\mathrm{Pb}$ semivariogram estimated as follows:

$\gamma_{\text {resid }}(\mathrm{h})=0.032 \times\{1-\exp (-\mathrm{h} / 1.5)\}$

Guess-field kriging interpolation as shown in Fig. 5 able to demonstrate distinct distribution outline at the area of missing data. It can be postulated that in case of minimal number of explanatory data, distribution of response variable in this study, i.e., $\mathrm{Pb}$ can be interpolated. Nonetheless, it is acknowledged that guess-field kriging can generate large uncertainty area as compared to ordinary kriging interpolation. The findings in the development of the missing data interpolation by utilising similar explanatory data, in this study, $\mathrm{Cr}$ from the ICP-MS analysis, has shown the ability of guess-field kriging in better managing of response variable data or in visualising hotspots in case of limited number of data obtained.

\subsection{Real impact pathway}

As part of the kriging analysis framework development, the real impact pathway was developed as a strategy for achieving sustainability of this work's overarching purpose (Fig. 6). This is aimed to provide answers to questions to is related to what this research works and make improvements based on research data as well as advocacy to exhibit the paybacks of research, education, and innovation to community, as discussed by Adam et al. (2018) and Morgan et al. (2013) of "Four As" in research impact assessment which are; analysis, advocacy, allocation, and accountability. Even if there is no constructive assessment for research impact in the region particularly in the aspect of scientific area and stakeholder requirement, the prima facie effectiveness of the framework can be developed by mapping out through the logical impact pathway. It is a model on the environment of the research work as a guide to generate outcomes and impact from the research output. Furthermore, it can offer variety of stakeholders or practitioners, a platform to communicate and collaborate to captivate the full spectrum of impact 
and benefits in the sustainability of the impact derive originally from the research work. Through the visualisation of the impact pathway, it will be able to support decisions to be made as well as providing outlook to enhance mission for achieving impact. This is part of the capacity or precondition for impact orientation to manifest the practise of creating impact (Springer-Heinze et al. 2003). The pathway effectiveness as a guide shall need to be included with self-evaluation for establishing direct benefits of the outputs at the targeted group of concern and the applied system as practise to evaluate the pathway to impact (Douthwaite et al. 2003).

Altogether, the framework development aimed to sustainably improving the livelihood of people residing near the closed landfill area apart from the environmental dimension. In between of the impact pathway subjected to harness benefits as outcome of the research work, process of innovation is to ascertain the dynamic change of environment which this process helps to revisit the program strategies in regular basis by obtaining effective training citizen as a prerequisite for succeeding outcome. The process of innovation is analogous to the bridge of the outcome and the sustainability's pillars of impact (social, economic, and environmental impact) vis-à-vis, the process of development (Fig. 6). Positive response by stakeholders with active participation of this movement of change will eventually experiencing impact as result. This is important part of learning approach on captivating different perspectives of innovation and development as discussed in-depth by Springer-Heinze et al. (2003) on strengthening impact orientation in an impact pathway analysis of agricultural research, although this work of risk assessment may encounter relatively different angle of the perspectives as a real challenge. Aside from that, frameworks deliver support by addressing key operational encounters and contrasts of research impact ranging from diverse fields, organisations, and countries (Adam et al. 2018).

Despite myriad impact frameworks and assessment methods readily available in literature to be incorporated by innovation to the kriging assessment framework for achieving sustainability in landfill aftercare management, this pathway is presenting a broad-spectrum yet definitive method for hypothesising impact developments, which provides a logical pathway for research preparation and able to map out potential stakeholder's engagement by facilitating communication. Although further analysis on detailing scaling up and scaling out of the projected dimensions as well as aggregated objectives for the pathway is needed to be developed for the intended impact to be achieved. Nevertheless, there is a limitation of the framework developed, which is feedback paths and direct impact paths is not pointed in the pathway as well as wider society categories of stakeholders that can be engaged at different stages of the framework. 


\section{Conclusions}

The framework on geostatistical analysis by ordinary and advanced kriging in this study was developed as a guide for the analysis of potentially toxic element interpolation at an unmeasured studied site. The framework is meant to deliberately identify the potentially toxic element distribution in a closed landfill with the existence of censored data on appropriate confidence levels. This study framework estimation was conducted via utilisation of VBA application, constructed by programming code, i.e., macros, which is effective to automate the interpolation and incurring a lesser extent of cost as compared to sophisticated software. On another note, the impact pathway developed in this study is the beginning step to map out a more complex environment with characterising direct benefits at different scale. This is described through the outputs of the works, which is expected to project direct benefits by change of socio- environment and wider impact spectrum detailing out from each dimension of sustainability, i.e., social, economic, and environment. Nevertheless, the impact pathway developed in this work is open for improvement by evolving through the dynamic of unprecedented knowledge expansion and impactful innovation processes as well as different views or perspectives of stakeholders.

\section{Funding}

This work was supported by Japan Society for the Promotion of Science and Universiti Malaya (Grant numbers [R11611] and [BR005-2016]) respectively.

\section{Competing Interests}

The authors have no relevant financial or non-financial interests to disclose.

\section{Author contributions}

All authors contributed to the study conception and design. Investigation, methodology, writing - original draft preparation were performed by Azizi Abu Bakar. Methodology, writing - review and analysis by Minoru Yoneda. The first draft of the manuscript was written by Azizi Abu Bakar and all authors commented on previous versions of the manuscript. All authors read and approved the final manuscript. 


\section{References}

Adam P et al (2018) ISRIA statement: ten-point guidelines for an effective process of research impact assessment. Health Research Policy and Systems 16(8) DOI 10.1186/s12961-018-0281-5

Agamuthu P, Fauziah SH (2010) Heavy metal pollution in landfill environment: A Malaysian case study. ICBBE 2010 1-4. https://doi.org/10.1109/ ICBBE.2010.5516886, 2010 4th International Conference on Bioinformatics and Biomedical Engineering

An XY, Wu QQ (2011) Co-word analysis of the trends in stems cells field based on subject heading weighting. Scientometrics 88(1):133-144

Azizi AB, Minoru Yoneda, Nguyen TT, Noor ZM (2019) Development of assessment for potentially toxic element contamination indicator in closed landfills and prospective geostatistical analysis. International Journal of GEOMATE 17(60):136-143

Bhunia GS, Shit PK, Chattopadhyay R (2018) Assessment of spatial variability of soil properties using geostatistical approach of lateritic soil (West Bengal, India). Annals of Agrarian Science 16(4):436-443

Chervona Y, Arita A, Costa M (2012) Carcinogenic metals and the epigenome: understanding the effect of nickel, arsenic, and chromium. Metall. https://doi.org/10.1039/c2mt20033c.

Cui YQ (2016) Cost-Effective Strategy for the Investigation and Remediation of Polluted Soil using Geostatistics and a Genetic Algorithm Approach. Thesis, Kyoto University

National Solid Waste Management Department (2022) Statistics on summary of landfill sites in Malaysia. https://jpspn.kpkt.gov.my/resources/index/user_1/Sumber_Rujukan/statistik/ringkasan_tapak_seluruh_ Malaysia.pdf. Accessed 27 January 2022

Department of Statistics Malaysia, 2022. Selangor. https://www.dosm.gov.my/. Accessed 27 January 2022 
Donovan C, Hanney S (2011) The ‘Payback Framework’ explained. Research Evaluation 20(3):181-183

Douthwaite B, Kuby T, van de Fliert E, Schulz S (2003) Impact pathway evaluation: an approach for achieving and attributing impact in complex systems. Agricultural Systems 78:243-265

Elwali B-EEAR, Yusoff I, Samsudin AR, Yaacob WZW, Rafek AGM (2010) Deterioration of groundwater quality in the vicinity of an active open-tipping site in west Malaysia. Hydrogeology Journal 18:9971006

Gámez AFC, Maroto JMR, Pérez IV (2019) Quantification of methane emissions in a Mediterranean landfill (Southern Spain). A combination of flux chambers and geostatistical methods. Waste Manag 87:93794

Hussein M, Yoneda K, Mohd-Zaki Z, Amir, A, Othman, N (2021). Heavy metals in leachate impacted soils and natural soils of different landfills in Malaysia: An alarming threat. Chemosphere 267:128874.

Krishnan G (2008) Dumpsite almost full at Ampar Tenang. The Star

Li Z, Ma Z, van der Kuijp TJ, Yuan Z, Huang L (2014). A review of soil heavy metal pollution from mines in China: pollution and health risk assessment. Sci Total Environ 468-469: 843-853

Lin YP, Yeh MS, Deng DP, Wang YC (2008) Geostatistical approaches and optimal additional sampling schemes for spatial patterns and future sampling of bird diversit. Glob Ecol Biogeogr 17(2):175-188

Ministry of Housing and Local Government (2004) The study on the safe closure and rehabilitation of landfill sites in Malaysia (Final Report Vol. 3: Guideline for safe closure and rehabilitation of MSW landfill sites). 
Mohd Adnan SNS, Yusoff S, Chua YP (2013) Soil chemistry and pollution study of a closed landfill site at Ampar Tenang, Selangor, Malaysia. Waste Management \& Research 31(6):599-612

Mombo S, Foucault Y, Deola F, Gaillard I, Goix S, Shahid M, Schreck E, Pierart A, Dumat C (2015) Management of human health risk in the context of kitchen gardens polluted by lead and cadmium near a lead recycling company. J Soils Sediments 16(4):1214-1224

Morgan Jones M, Grant J et al (2013) Making the grade: methodologies for assessing and evidencing research impact. In: Dean A, Wykes M, Stevens H (ed) Seven Essays on Impact. DESCRIBE project report for JISC, Exeter: University of Exeter, UK pp 25-43

Pei T, Qin C-Z, Zhu AX, Yang L, Luo M, Li B, Zhou C (2010) Mapping soil organic matter using the topographic wetness index: a comparative study based on different flow-direction algorithms and kriging methods. Ecol Indic 10(3):610-619

Pouladi N, Møller AB, Tabatabai S, Greve MH (2019) Mapping soil organic matter contents at field level with Cubist, Random Forest and kriging. Geoderma 342:85-92

Rushton L, (2003) Health hazards and waste management. Brit Med Bull 68:183-197

Sakawi et al (2013) The analysis of heavy metal concentration per distance and depth around the vicinity of open landfill. Res J Appl Sci Eng Technol 5(24):8619-8625

Sharifah-Norkhadijah SI, Latifah AM (2013) The challenge of future landfill: A case study of Malaysia. Journal of Toxicology and Environmental Health Sciences 5(6):86-96

Springer-Heinze A, Hartwich F, Henderson JS, Horton D, Minde I (2003) Impact pathway analysis: an approach to strengthening the impact orientation of agricultural research. Agricultural Systems 78:267-285 
Syahirah Siti Nur, Mohd A, Sumiani Y, Yan Piaw C (2013) Soil chemistry and pollution study of a closed landfill site at Ampar Tenang. Waste Manag Res 31(6):599-612. https://doi.org/10.1177/0734242X13482031

Taha MR, Yaacob WZW, Samsudin AR, Yaakob J (2011) Groundwater quality at two landfill sites in Selangor, Malaysia. Bulletin of the Geological Society of Malaysia 57:13-18

Tarmudi Z, Abdullah ML, Md Tap AO (2009) An overview of municipal solid wastes generation in Malaysia. J. Tek 51:1-15

Yarus JM, Chambers RL (2006) Practical geostatistics - An armchair overview for petroleum reservoir engineers. Journal of Petroleum Technology 120-130

Yigini Y, Panagos P (2016) Assessment of soil organic carbon stocks under future climate and land cover changes in Europe. Sci Total Environ 557-558:838-850

Yusoff I, Alias Y, Yusof M, Ashraf MA (2013) Assessment of pollutants migration at Ampar Tenang landfill site, Selangor, Malaysia. Sci Asia 39(4):392-409. https://doi.org/10.2306/scienceasia15131874.2013 .39 .392

Vaccari M, Vinti G, Tudor T (2018) An analysis of the risk posed by leachate from dumpsites in developing countries. Environments 5(9):99. https://doi.org/ 10.3390/environments5090099

Webster R, Oliver MA (2007) Geostatistics for Environmental Scientists (2nd Edition). John Wiley \& Sons, Chichester

Zhang X, Yang L, Li Y, Li H, Wang W, Ye B (2012) Impacts of lead/zinc mining and smelting on the environment and human health in China. Environ Monit Assess 184(4):2261-2273 
Zhao Y, Li Y, Fan D, Song J, Yang F (2021) Application of Kernel Extreme Learning Machine and Kriging Model in Prediction of Heavy Metals Removal by Biochar. Biores. Technol. https://doi.org/10.1016/j.biortech.2021.124876

Zhen J, Pei T, Xie S (2019) Kriging methods with auxiliary nighttime lights data to detect potentially toxic metals concentrations in soil. Sci Total Environ 659:363-371 


\section{Figures}

Figure 1

a

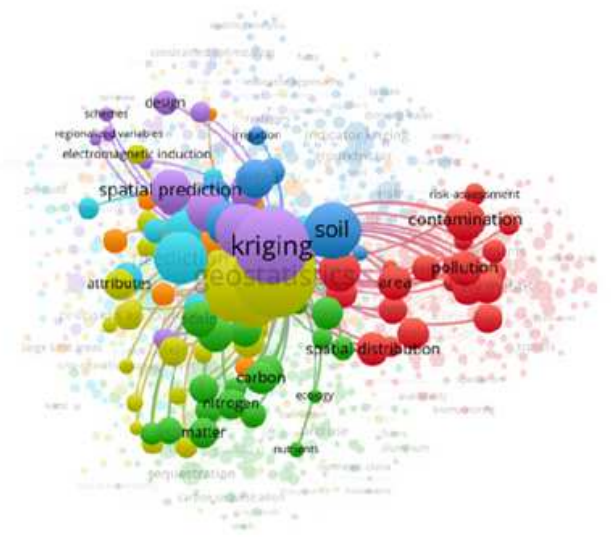

b

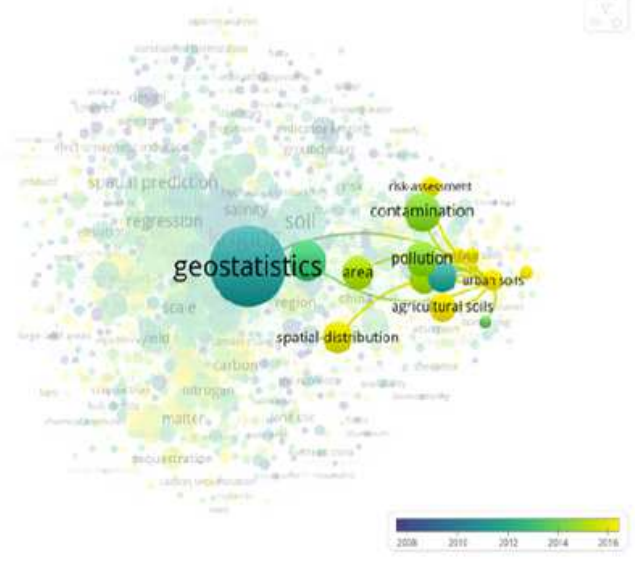

\section{Figure 1}

Bibliometrics analysis based on keyword analyses in relation to kriging and soil research by operating Web of Science (WoS) core collection within period of 1970-2020. a) Co-occurrence matrix. b) Overlay visualisation of the keywords. 


\section{Figure 2}

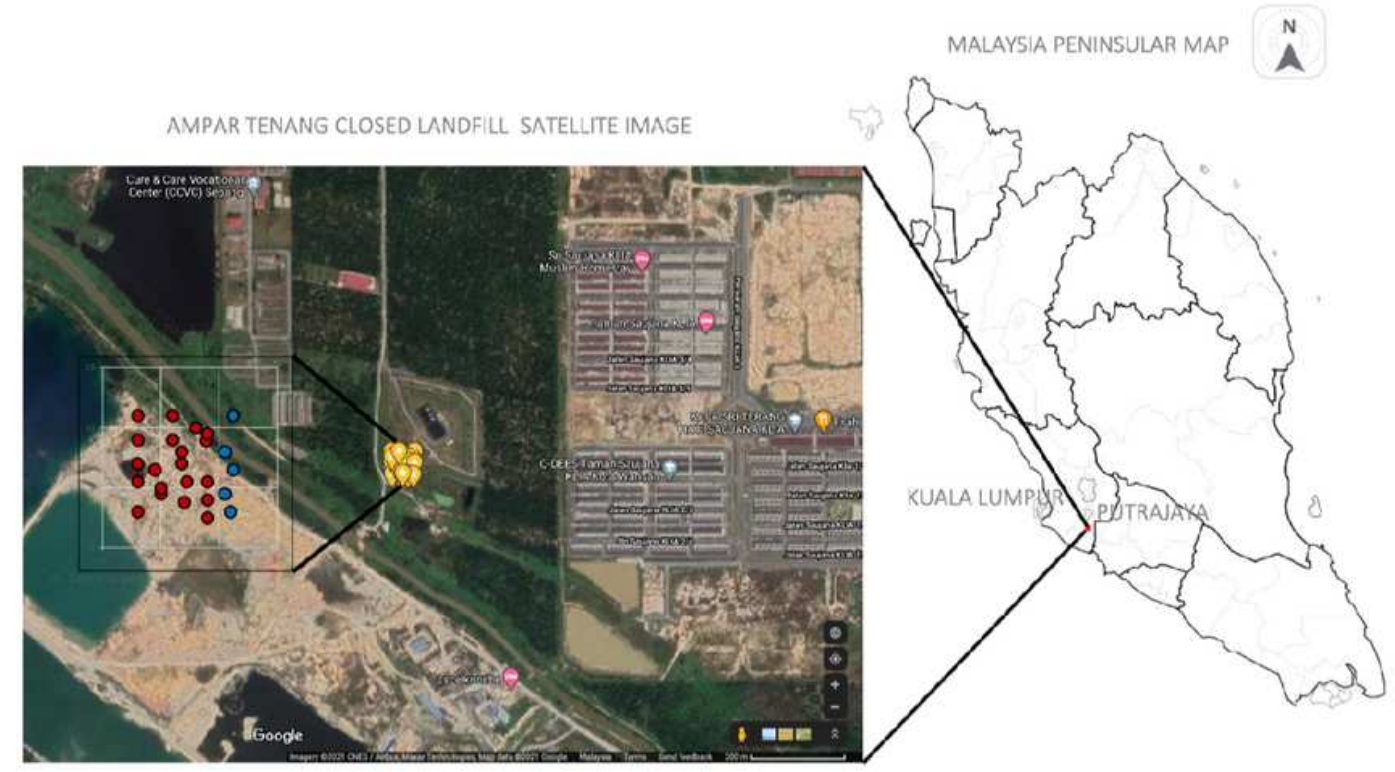

\section{Figure 2}

Map of the location of the Ampar Tenang non-sanitary closed landfill tagged with sampling points in Sepang, Selangor, and the sampling grid in a $5 \mathrm{~m} \times 5 \mathrm{~m}$ diagram (insert). The bubbles in the grid denote the location of soil samples (tagged in map) where the blue bubbles refer to the missing data from inductively coupled plasma spectrometry analysis of Pb (Imagery (C2021 by Google Maps, 2021). 
Figure 3

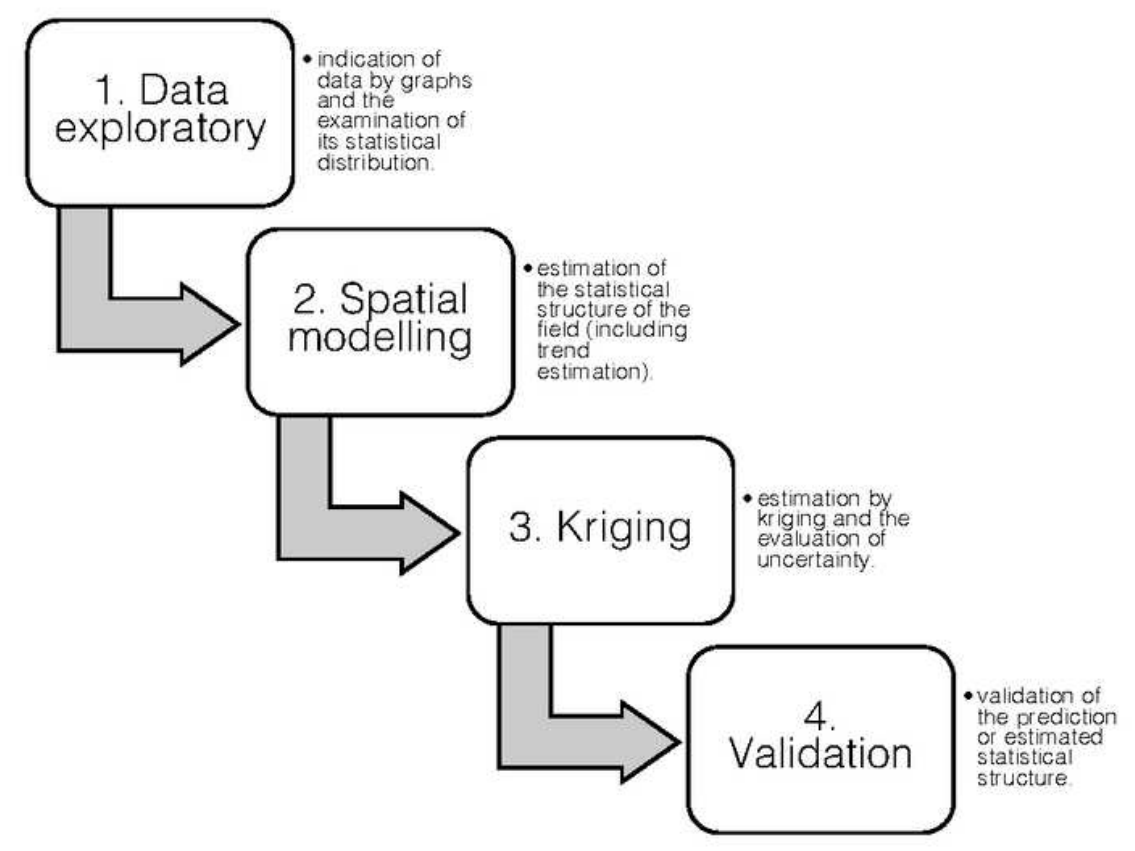

\section{Figure 3}

Fundamental geostatistical analysis procedures applied in this work. 


\section{Figure 4}

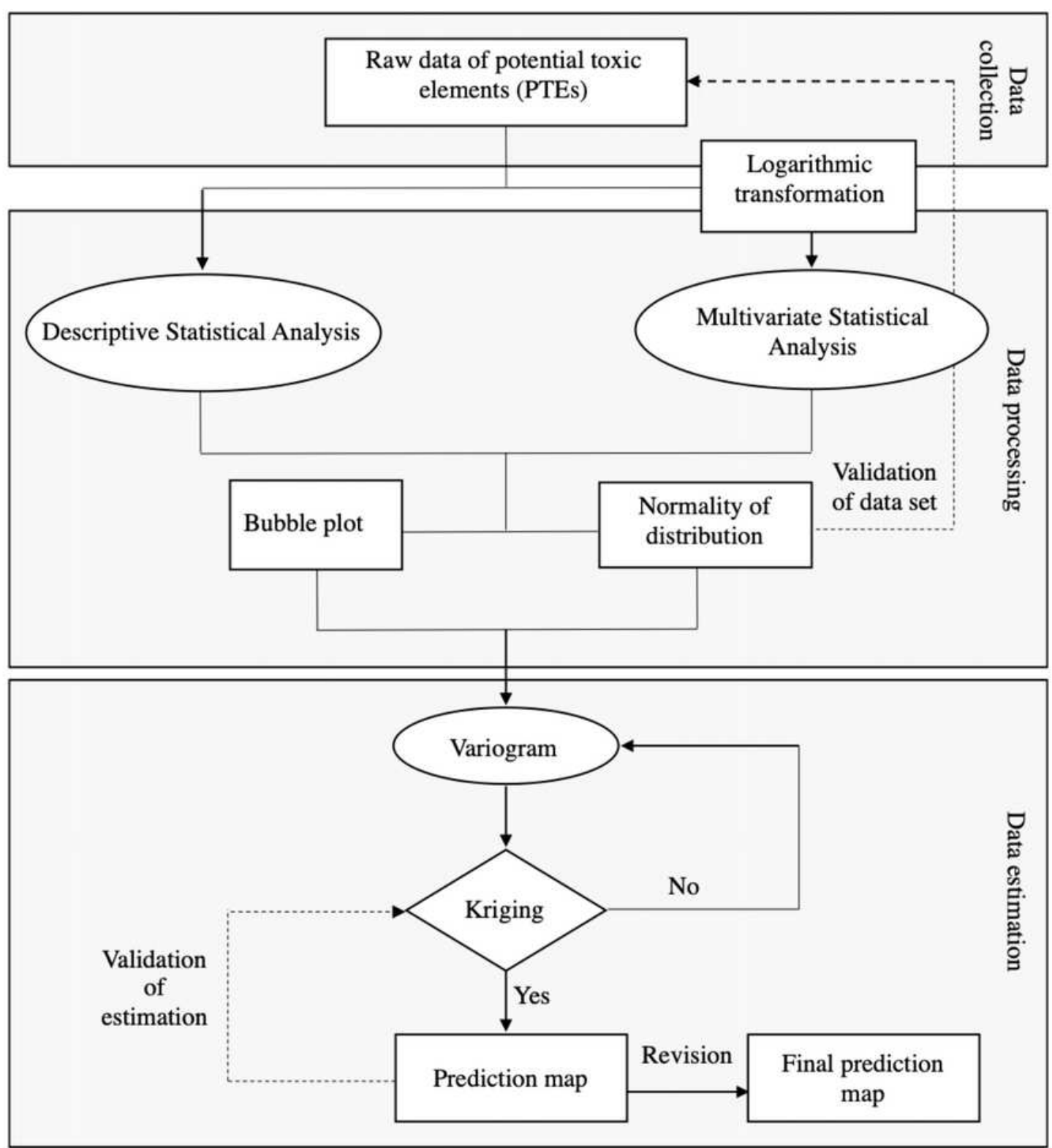

Figure 4

Diagram of the ordinary kriging framework applied in this study via the application of Visual Basic for Applications (VBA). 


\section{Figure 5}

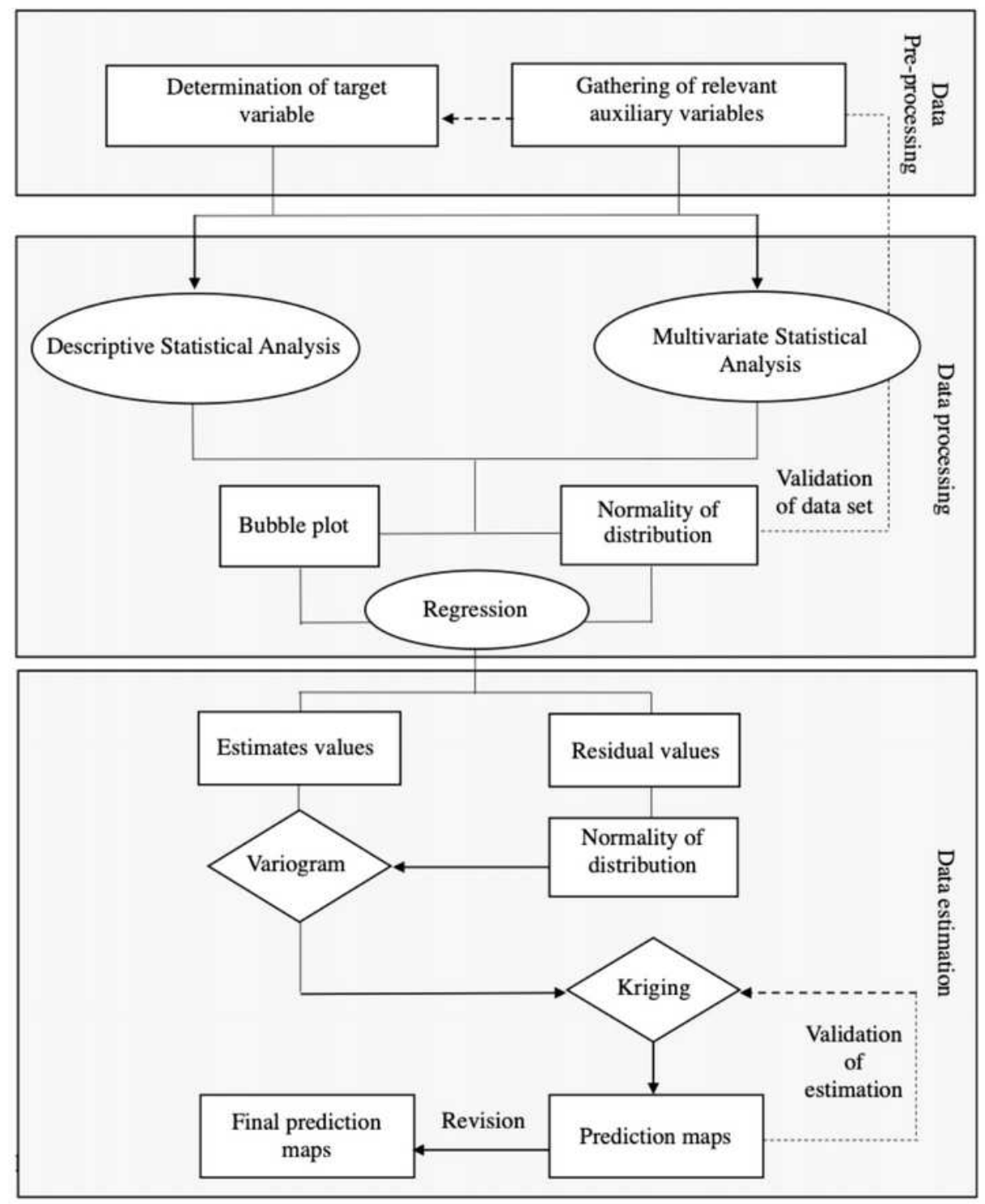

\section{Figure 5}

Diagram of the advanced kriging (regression and guess-field) framework applied in this study via the application of VBA. The target variable tested in this study was $\mathrm{Pb}$, and the auxiliary variable was $\mathrm{Cr}$. 
Figure 6
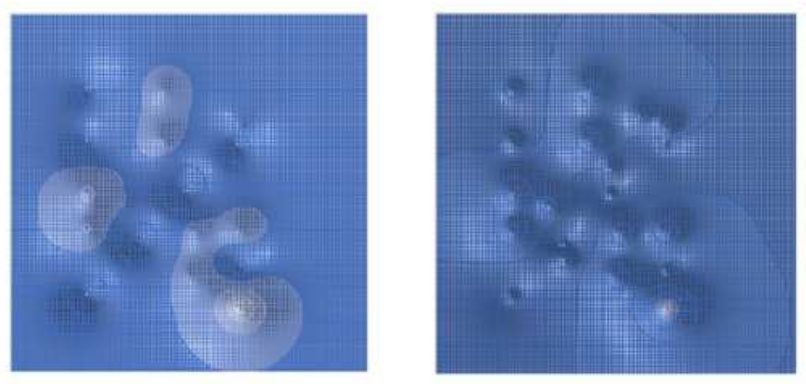

ㅁ1.25-1.4

ㅁ1.1-1.25

๑0.95-1.1

๑ 0.8-0.95

0.65-0.8
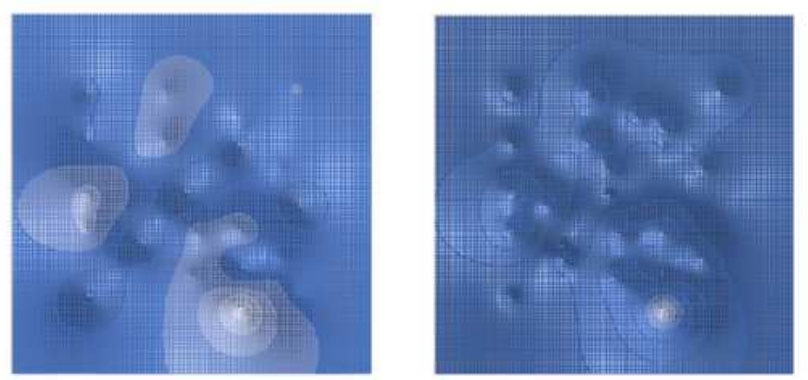

๑ 0.5-0.65

$\square 0.35-0.5$

$\square 0.2-0.35$

$\square 0.05-0.2$

미 -0.1-0.05

\section{Figure 6}

Above: Ordinary kriging (OK) interpolation of $\mathrm{Pb}$ (left) and 95th percentile value of the $\mathrm{OK}$ (right). Below: Guess-field kriging (GFK) of $\mathrm{Pb}$ (left) and 95th percentile value of the GFK (right) 
Figure 7

\begin{tabular}{|c|c|c|c|c|c|c|c|c|}
\hline \multicolumn{3}{|c|}{$\begin{array}{l}\text { Research-dependent / } \\
\text { Internal-to-research strategy }\end{array}$} & \multicolumn{6}{|c|}{ Research-independent / External-to-research strategy } \\
\hline Research input & Research output & & & Research outcome & & & $\begin{array}{l}\text { Social, economic, and } \\
\text { environmental impact }\end{array}$ & Sustainability \\
\hline $\begin{array}{l}\text { - Research } \\
\text { resources } \\
\text { (researcher } \\
\text { and } \\
\text { laboratory). } \\
\text { - Research } \\
\text { tools } \\
\text { (geochemical } \\
\text { indices and } \\
\text { geostatistical } \\
\text { techniques. }\end{array}$ & $\begin{array}{l}\text { - Geochemical } \\
\text { results: } \\
\text { potentially toxic } \\
\text { element content } \\
\text { and } \\
\text { contamination } \\
\text { level. } \\
\text { - Geostatistical } \\
\text { analysis: } \\
\text { distribution } \\
\text { estimation of } \\
\text { potentially toxic } \\
\text { element at the } \\
\text { closed landfill } \\
\text { and decision } \\
\text { making. } \\
\text { - Framework for } \\
\text { environmental } \\
\text { risk assessment. }\end{array}$ & 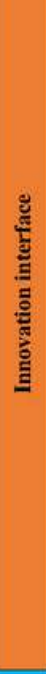 & $\begin{array}{l}\text { Process of } \\
\text { potentially } \\
\text { toxic } \\
\text { element } \\
\text { assessment } \\
\text { innovation: } \\
\text { - Effective } \\
\text { training } \\
\text { for } \\
\text { citizens }\end{array}$ & $\begin{array}{l}\text { - Change of public } \\
\text { perception for } \\
\text { recreation activities } \\
\text { on closed landfill } \\
\text { topsoil. } \\
\text { - Change in nearby } \\
\text { residences' } \\
\text { organisational } \\
\text { structure and } \\
\text { practices for open- } \\
\text { minded attitude } \\
\text { activities at the } \\
\text { closed landfill. } \\
\text { - Change of landfill } \\
\text { management } \\
\text { practices on } \\
\text { environmental risk } \\
\text { assessment as well } \\
\text { as local authority. }\end{array}$ & 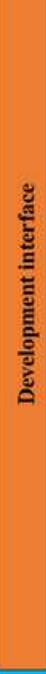 & $\begin{array}{l}\text { Process of } \\
\text { potentially } \\
\text { toxic element } \\
\text { assessment } \\
\text { development: } \\
\text { - Positive } \\
\text { response } \\
\text { from } \\
\text { stakeholders } \\
\text { with active } \\
\text { involvement }\end{array}$ & $\begin{array}{l}\text { Development of social } \\
\text { cohesion in social welfare } \\
\text { and Research \& } \\
\text { Development investment } \\
\text { from related industries in } \\
\text { waste management and } \\
\text { public engagement, } \\
\text { including non- } \\
\text { governmental } \\
\text { organisations. } \\
\text { - Creation of new } \\
\text { economic sector } \\
\text { developed from the } \\
\text { utilisation of the closed } \\
\text { or repurposed landfill. } \\
\text { - Public policy as new law } \\
\text { to enforce constant } \\
\text { assessment of potentially } \\
\text { toxic elements for } \\
\text { national health security or } \\
\text { the review of existing law } \\
\text { for the improvement of } \\
\text { the landfill environment. }\end{array}$ & $\begin{array}{l}\text { - Assessment of } \\
\text { potentially toxic } \\
\text { element scale up } \\
\text { to regional } \\
\text { adherence as result } \\
\text { of replication. } \\
\text { - Reconciliation of } \\
\text { governance as a } \\
\text { result from } \\
\text { continuous social } \\
\text { movement, } \\
\text { subsistence } \\
\text { economy that } \\
\text { evolves from } \\
\text { constant financial } \\
\text { commitment and } \\
\text { enhancement of } \\
\text { environmental } \\
\text { health protection } \\
\text { from zero waste } \\
\text { diversion to } \\
\text { landfill. }\end{array}$ \\
\hline \multicolumn{6}{|c|}{ Research scheme } & \multicolumn{3}{|c|}{ Impact scheme } \\
\hline
\end{tabular}

\title{
Figure 7
}

The logical framework of the pathway to real impact for potentially toxic element assessment in a closed landfill.

\section{Supplementary Files}

This is a list of supplementary files associated with this preprint. Click to download.

\author{
- SupportingInformationSERRAAzizi.pdf
}

